\title{
EVASÃO DE DISCENTES NO CURSO DE ENGENHARIA QUÍMICA NA UNIVERSIDADE FEDERAL DE MATO GROSSO - UFMT: SOB A PERSPECTIVA DA AUTOAVALIAÇÃO INSTITUCIONAL E ACADÊMICA
}

DOI: 10.37702/2175-957X.COBENGE.2021.3560

Maria Luiza Ribeiro da Silva - luizaaribeiro7@gmail.com

Universidade Federal do Mato Grosso

Rua doze 240

78068-744 - Cuiabá - MT

Luan Claiton de Moraes Marostegan - luanmoraes.mail@gmail.com

Universidade Federal de Mato Grosso

Avenida Porto Alegre 1900

78894-036 - Sorriso - MT

Gabriel Henrique Justi - prof.ghjusti@gmail.com

Universidade Federal de Mato Grosso

Rua Av. das Palmeiras s/n

78075-850 - Cuiabá - MT

Resumo: Este artigo trata do resultado obtido através da pesquisa sobre a evasão de discentes no curso de Engenharia Química - UFMT sob a perspectiva da autoavaliação institucional e acadêmica. Foi realizado com a finalidade de verificar os motivos que levam a desistência no curso, relacionado a aspectos institucionais de ensino, organização administrativa do curso e vínculo acadêmico - desistentes, em trancamento e matriculados. Para a realização desta pesquisa foi elaborado um questionário via "Formulário Google", submetido ao comitê de Ética da UFMT com aprovação para a realização da pesquisa e estratificação dos dados. $O$ formulário foi aplicado aos discentes e ex-discentes do curso (ingressantes entre os anos 2014/2 e 2019/2), caracterizando como metodologia quanti-qualitativa com enfoque descritivo e interpretativo na análise dos dados. Os dados mostraram resultados relevantes sobre a pesquisa, visto que os pontos mais críticos sob a perspectiva dos discentes em relação aos vínculos institucionais referem-se a critérios quanto à satisfação do curso e a matriz curricular que não atendem suas expectativas. Aos critérios relacionados ao ensino se refere a adaptabilidade dos 


\section{COBENGE e I Simpósio Internacional

estudantes ao curso, tendo avaliado como mediano ou fraco a satisfação com esses aspectos. Desse modo, o estudo aponta que a autoavaliação se faz relevante para compreender o ponto de vista dos alunos quanto a sua satisfação em relação ao curso, devendo ser reformulada para adaptar-se continuamente a medida de oferecer possibilidade de criação de políticas institucionais como solução à evasão do curso.

Palavras-chave: Evasão. Autoavaliação. Aspectos institucionais 


\section{EVASÃO DE DISCENTES NO CURSO DE ENGENHARIA QUÍMICA NA UNIVERSIDADE FEDERAL DE MATO GROSSO - UFMT: SOB A PERSPECTIVA DA AUTOAVALIAÇÃO INSTITUCIONAL E ACADÊMICA}

\section{INTRODUÇÃO}

A educação é caracterizada como um processo de humanização essencial para o desenvolvimento do indivíduo para exercer seu papel de cidadão e qualificação no mercado de trabalho. De acordo com Humerez e Jankevicius (2015), a formação educacional de base superior iniciou-se no Brasil no século XIX com a implantação de cerca de 10 Instituições de Ensino Superior - IES. Ao início do século XX, as IES começaram a passar por mudanças significativas de ensino, com a criação de novas faculdades e institutos tecnológicos e de pesquisa no território nacional.

Conforme Agapito (2017, p.131), na primeira década dos anos 2000, observou-se uma intensificação nas ofertas de cursos na educação superior com a "implementação de medidas provisórias, projetos de leis, leis e decretos viabilizando o aumento do número de matrículas no ensino superior nas IES públicas e manteve-se o crescimento de IES privadas", com ênfase nas áreas de ciências sociais nos cursos de negócios e direito, ciências exatas em educação e engenharia e ciências naturais, pela área da saúde e bem-estar.

O curso de engenharia no Brasil apresentou um crescimento de ingressantes nos últimos tempos, com o surgimento de novas oportunidades na formação superior que abrange além dos conhecimentos técnicos, a busca por profissionais capazes de liderar, inovar e administrar as demandas do mercado de trabalho.

Segundo Macedo e Sapunaru (2016, p.2), a engenharia contemporânea pode ser vista como a arte de aplicar conhecimentos científicos, na criação de estruturas, dispositivos e processos, ou seja, a medida que há uma necessidade de solucionar problemas e gerar soluções, a engenharia torna-se necessária para atender de forma adequada e tecnológica às necessidades da sociedade, com conhecimentos de ordem matemática, física, química e expressão gráfica.

Neste contexto, apesar de expressivo aumento da oferta e de matrículas efetuadas em cursos de Engenharia, os cursos apresentam alta taxa de evasão, no que diz respeito ao dado de desligamento formal ou não do curso e/ou instituição, gerando vaga ociosa, segundo Alves e Mantovani (2016, p. 27).

Em virtude disso, Matta, Lebrão e Heleno $(2017$, p. 7) ressaltam que a atuação das instituições no processo do estudante à vida acadêmica ocorra por intermédio da utilização de serviços de apoio psicológico e psicossocial, contribuindo para permanência dos estudantes, principalmente àqueles que estão em seu primeiro ano de curso e estão expostos aos desafios do período de ingresso. Para esses, mais especificamente, os autores sugerem que se considere os aspectos condicionais amplamente, uma vez que para além do impacto gerado ao contexto da academia, surgem a exposição a outras ambientações.

Neste contexto, o presente trabalho se orienta com o objetivo de analisar a evasão no curso de Engenharia Química - UFMT, por meio das percepções dos discentes através dos vínculos institucionais - matrícula regular, em trancamento e desistência, e por meio da análise da autoavaliação referente aos aspectos de ensino e a organização administrativa do curso. 


\section{REFERENCIAL TEÓRICO}

\subsection{Evasão no ensino superior}

A evasão de discentes no sistema educacional é um problema que ocorre em todos os tipos de instituições e amplia-se a busca por suas causas. Segundo Rodriguez (2011, p.4), a evasão é caracterizada pelos estudantes que abandonaram, trancaram, desligaram-se ou transferiram-se para outra IES.

Cordasso et al. (2016, p.2), retrata neste contexto que a evasão é resultante de inúmeros fatores internos e externos que vem atingindo os discentes de IES públicas e privadas, interferindo em distintos aspectos.

A evasão está relacionada a diversos fatores, divididos em internos e externos. Os fatores internos são ligados ao curso, e podem ser classificados em: infraestrutura, corpo docente e a assistência socioeducacional. Os fatores externos relacionam-se ao aluno, tais como: vocação, aspectos socioeconômicos e problemas de ordem pessoal. (PAREDES, 1994, p.12).

Filho et al. (2007, p.2), ressalta que há uma grande perda pelos discentes que iniciam, mas não terminam o curso, como desperdícios sociais, acadêmicos e econômicos.

Segundo o Mapa do Ensino Superior, em 2018 o Brasil atingiu 30,1\% de evasão na rede privada e $18,5 \%$ na rede pública, sendo caracterizado como principais motivos de desistência a política de financiamento estudantil ineficiente, dificuldades de acesso ao ensino público e falta de motivação dos jovens.

\section{Evasão nos cursos de engenharia}

No Brasil os cursos de engenharias apresentam alto índice de evasão, sendo de $55,59 \%$ a taxa média de desistência, segundo dados da Confederação Nacional da Indústria (CNI). Martins et al. (2014, p.2), retrata que a média de desistentes na engenharia é referida pela deficiência na formação básica, na falta de conhecimento nas áreas de física, matemática e química, bem como no domínio e hábitos de estudos e pesquisas.

Os autores Oliveira et al. (2010, p.143) ressalta também que, seriam necessárias as IES caracterizarem o desempenho dos discentes, principalmente no ciclo básico e criar mecanismos e políticas institucionais que buscassem minimizar os problemas de retenção, reprovação e evasão nos cursos de engenharia.

De acordo Gomez et al. (2015, p.2), formam-se no Brasil cerca de 32 mil engenheiros a cada ano, um número preocupante devido a grande quantidade de vagas ofertados nas IES, resultando em novos métodos de implementação de políticas públicas "para expansão das vagas nas universidades, não somente para abertura de novas vagas nos cursos de engenharia, mas para garantir a permanência do estudante até a sua formação." Conforme dados divulgados pelo Inep em 2016, havia no país cerca de 4.193 cursos de engenharias e 1 milhão de discentes matriculados, destacando os cursos de engenharia civil, elétrica e mecânica.

Segundo Reis et al. (2012, p.3), "a área de conhecimento de Engenharia, Produção e Construção apresenta evasão média de $21 \%$ ao ano", tendo uma maior taxa de evasão no primeiro ano de curso com cerca de duas a três vezes maiores do que os anos posteriores, devido aos fatores socioeconômicos e institucionais. 
Entre os socioeconômicos, podem ser citados: inserção precoce no mercado de trabalho; a formação insuficiente em exatas; desempenho insatisfatório nas avaliações iniciais; mercado de trabalho desfavorável. Entre as institucionais: carga alta de estudos; mau relacionamento professor-aluno; corpo docente sem vocação para ensinar; ausência de matérias com aplicação prática; concentração excessiva de matérias básicas; estrutura insuficiente em laboratórios (JÚNIOR et al. 2017, p.5).

\subsection{Métodos de avaliação como instrumento de gestão}

A autoavaliação segundo Depresbiteris (2005, p.3), pode ser sucintamente definida como o ato de uma pessoa avaliar a si próprio, ou seja, "a autoavaliação supõe crítica e afastamento para reflexão, estimulando um diálogo interno construtivo".

No contexto de autoavaliação institucional, Lopes (2018, p.2) retrata como uma ferramenta necessária, inovadora e pertinente para as IES, uma vez que o discente ou docente faz uma avaliação consciente por si e para si mesmo na busca do melhor conhecimento pessoal e regulação de suas ações ou condutas.

De acordo Silva et al. (2007, p.2), a autoavaliação é uma concepção contemporânea de avaliações que pressupõe não só instrumentos tradicionais aplicados para avaliar os alunos, a instituição e os professores, mas também como uma forma de novas alternativas em suas aplicações.

Segundo o Sistema Nacional de Avaliação da Educação Superior - SINAES (2004, p.10), a autoavaliação é um importante instrumento para a tomada de decisão, tendo como resultados um relatório abrangente e detalhado, contendo análises, críticas e sugestões a fim de identificar as fragilidades e as potencialidades das instituições.

Silva et al. (2007, p.3) ressaltam também que a autoavaliação, pode alcançar bons resultados, uma vez que, as pessoas que passam por este processo estejam cientes dos critérios para sua aplicação, com objetividade nas questões gerais e específicas, além da clareza quanto às necessidades dos discentes ou docentes, pois se a autoavaliação "for utilizada de maneira impressionista, em vez de ser um instrumento de desenvolvimento, poderá se tornar fonte de desentendimento dentro da instituição".

\section{METODOLOGIA}

Em conformidade aos objetivos deste trabalho, a metodologia abordada é de caráter quanti-qualitativo, uma vez que se mostra mais adequado para o tipo de investigação proposta. Assim, busca-se adotar enfoque descritivo e interpretativo para análise dos dados.

Quanto aos procedimentos técnicos, foi realizado uma pesquisa eletronicamente por meio de formulário elaborado na plataforma Google Forms, sendo submetido para aprovação para realizar a análise dos dados na Plataforma Brasil (CAAE $n^{\circ}$ 33531620.3.0000.5690), aplicado aos discentes e ex-discentes (ingressantes entre os anos 2014/2 e 2019/2) do curso de Engenharia Química da Faculdade de Engenharia da Universidade Federal de Mato Grosso - Campus Universitário de Várzea Grande, que voluntariamente se dispuseram a respondê-lo. A versão completa deste formulário poderá ser solicitada diretamente aos autores.

Optou-se por não utilizar e nem levantar dados pessoais dos participantes (nomes, documentos, e-mails pessoais, entre outros). De modo que, a proposta dessa pesquisa seja captar o ponto de vista de elementos principais e essenciais em um processo de formação educacional. Por sua vez, estes elementos incidentes no processo educativo se 
dão com base na sua perspectiva pessoal (vivências, critérios socioeconômicos etc.), bem como da sua avaliação institucional.

Os critérios apresentados foram, dessa forma, definidos com base nas Orientações Gerais para o Roteiro de Autoavaliação das Instituições do MEC para além de outras observações em questionários levantados nas literaturas que buscaram compreender os níveis de adaptação, rendimento acadêmico e permanência de estudantes nos cursos universitários com ênfase aos de engenharia. Para tanto, foram definidos três blocos ao longo do questionário: 1- Questões relativas ao contexto do(a) Estudante; 2- Questões relativas ao contexto do curso de Engenharia Química: Ensino, Instalações Físicas e Organização Administrativa; 3- Questões relativas ao contexto de vínculo ao curso de Engenharia Química. Na maior parte da pesquisa, os avaliadores tiveram de estabelecer sua percepção quanto aos elementos relacionados à formação em uma escala de grau de impacto que varia numa escala tipo Likert de cinco pontos.

Esses graus de impacto variam entre o "Muito Fraco" ao "Muito Ruim" com atribuições numéricas de 1 a 5 , respectivamente. Os outros itens, por sua vez, foram utilizados como forma de compreender as expectativas quanto à graduação de Engenharia Química dos discentes, bem como o seu perfil socioeconômico.

\section{RESULTADOS}

O formulário foi aplicado aos discentes do curso entre os meses de outubro a novembro de 2020, totalizando 67 respostas. De acordo com a Figura 1, dentre os entrevistados, $61,19 \%$ foram mulheres e $38,81 \%$ homens. Nota-se também que o público masculino se autodeclara pardos com $42,21 \%$, já o feminino com $48,78 \%$ se autodeclara brancos.

Figura 1 - Análise geral dos participantes.

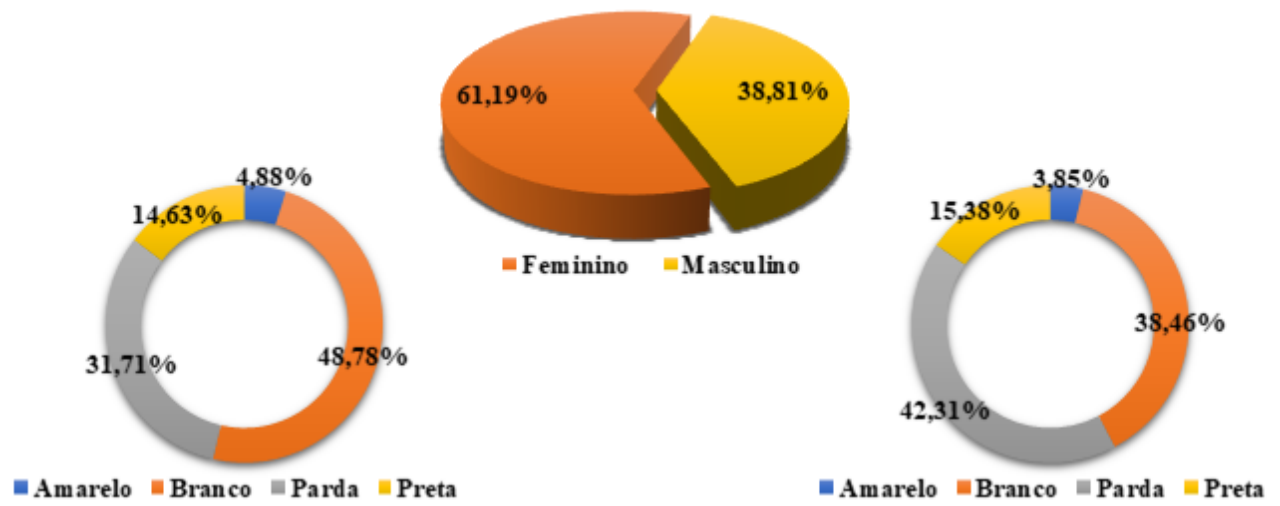

Fonte: Os autores (2021).

$\mathrm{Na}$ Figura 2, é feita uma análise sobre os critérios socioeconômicos dos entrevistados e sobre suas nacionalidades. Percebe-se que a maior parte dos discentes estudaram em escola pública com $52,2 \%$ e apenas $38,8 \%$ tiveram um ensino em escolas particulares. Além disso, a diversidade brasileira é perceptível, visto que $37,7 \%$ vieram de outras regiões do país, caracterizando um curso diverso com distintas culturas. Aos aspectos socioeconômicos, foi considerado uma análise relacionada com o somatório das rendas das pessoas que convivem juntamente com o discente (levando em conta o salário-mínimo no ano de 2020 de $\mathrm{R} \$ 1.045,00), 31,3 \%$ dos entrevistados responderam 
que sua renda varia de 1 a 3 salários-mínimos e de 3 a 6 salários-mínimos, 22,4\% somam mais de 6 salários-mínimos, enquanto $11,9 \%$ com apenas 1 salário-mínimo.

Figura 2 - Análise socioeconômica, acadêmica e regional.

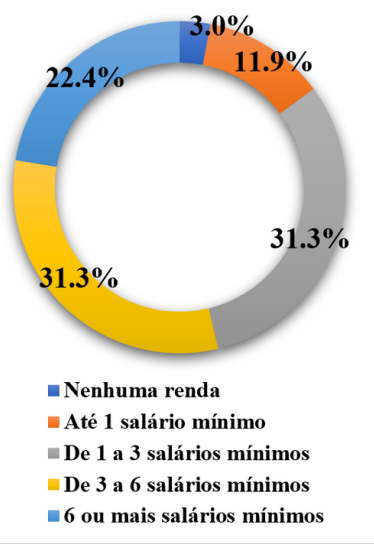

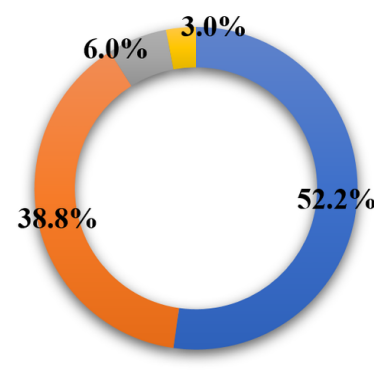

- Todo em escola pública

- Todo em escola particular

- Maior parte em escola pública

Maior parte em escola particular

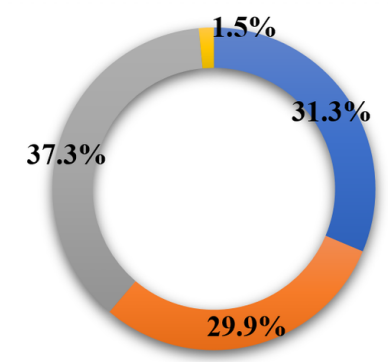

匹 Cuiabá ou baixada cuiabana

n Outras regiões do estado de Mato Grosso

๓ Outras regiōes do Brasil

Sou estrangeiro (a)

Fonte: Os autores (2021).

Dentre os entrevistados, todos ingressaram no curso de Engenharia Química por meio do Sistema de Seleção Unificada (SISU). Além disso, nota-se que em relação aos vínculos institucionais, $85 \%$ dos estudantes encontram-se matriculados no curso, $6 \%$ em trancamento e $9 \%$ são desistentes.

Conforme a Figura 3 é feita uma análise da perspectiva dos discentes quanto ao curso em relação ao vínculo de matriculados.

Figura 3 - Análise do vínculo institucional: matriculados.
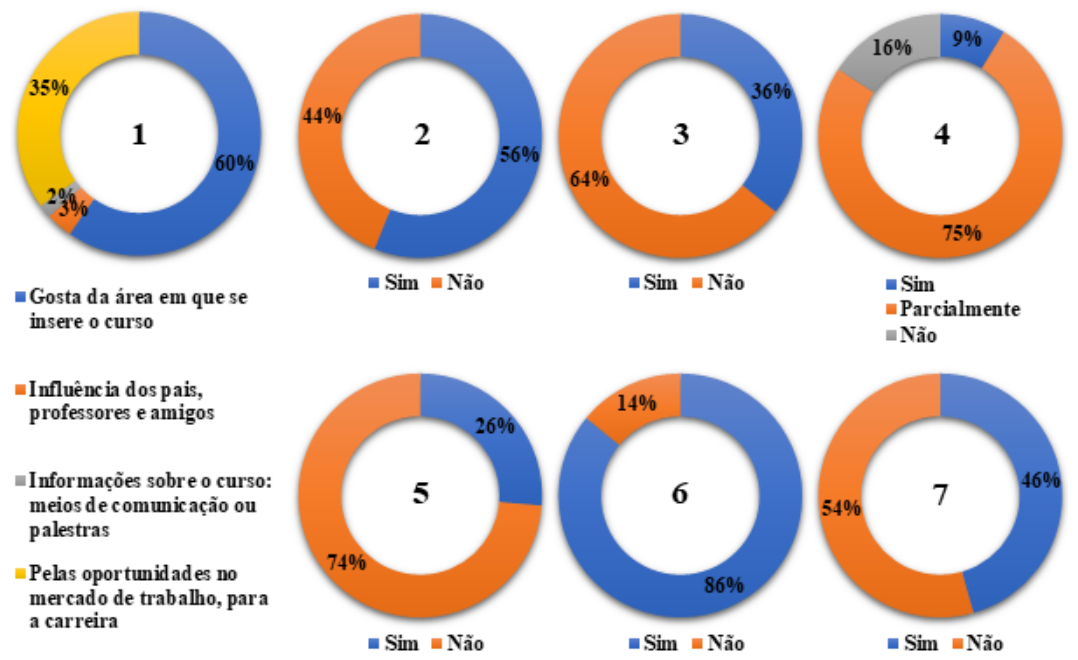

Fonte: Os autores (2021).

Nota-se que de acordo com (1), $60 \%$ responderam que a escolha do curso foi devido a gostar da área na qual o curso se insere, e $35 \%$ se interessaram pela oportunidade no mercado de trabalho, visto que é uma área de vasta experiência. Em (2) é notório que $56 \%$ dos entrevistados apresentaram dúvidas se ingressaria no curso, após ter sido chamado pelo SISU. Além disso, 64\% dos matriculados em (3) não apresentam 
satisfação com o curso e $75 \%$ como mostra em (4) estão parcialmente satisfeitos com a grade curricular e disciplinas. Os itens (5-6-7) tratam sobre a questão socioeconômica dos discentes, na qual $75 \%$ exercem atividade remunerada enquanto realiza o curso, visto que dentre estes $46 \%$ apresentaram dificuldades financeiras que o motivaram a trabalhar durante a graduação e $86 \%$ conseguem se manter financeiramente com ajuda de familiares e amigos.

A Figura 4 está relacionada ao vínculo dos matriculados em trancamento. Nota-se que no item (1), $75 \%$ dos entrevistados responderam que o curso não atende suas expectativas quanto a matriz curricular e em (2), 100\% responderam que a ocorrência de relações interpessoais (aluno-aluno/aluno-professor) influenciou o trancamento do curso. Os itens seguintes estão relacionados às questões socioeconômicas: em (3) $50 \%$ disseram que teve algum tipo de impedimento financeiro que o levaram a trancar o curso, enquanto em (4), 100\% já trabalhava antes do ingresso à faculdade. Os itens (5-6) discorrem que $50 \%$ dos discentes tiveram que trabalhar durante a graduação para conseguir se custear e $50 \%$ devido a isso, optou-se por trancar o curso. Em (7), $75 \%$ exercem atualmente alguma atividade remunerada.

Figura 4 - Análise do vínculo institucional: em trancamento.

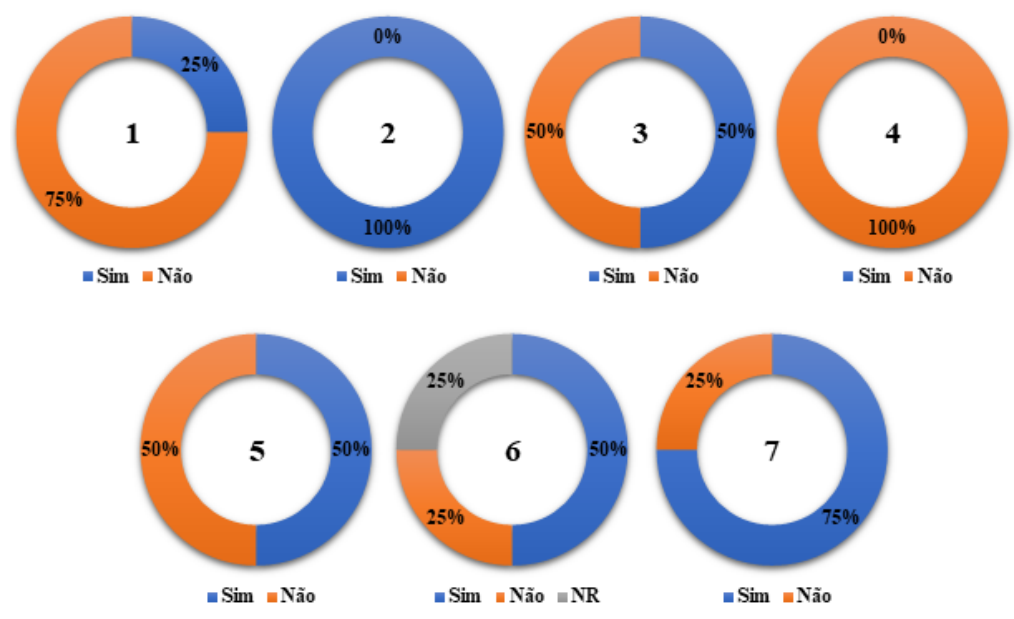

Fonte: Os autores (2021).

A Figura 5 trata-se dos discentes desistentes do curso. Em (1), 83\% responderam que o curso não atendeu suas expectativas e em (2) $100 \%$ das respostas dos entrevistados retratam que o curso também não atendeu suas expectativas em relação à matriz curricular. Nos itens (3-4), estão relacionados às ocorrências, $67 \%$ mostraram que as reprovações os levaram a desistir do curso e $67 \%$ as relações interpessoais (alunoaluno/aluno-professor) que ocasionou isso. Em (5) $83 \%$ responderam que não foi o impedimento financeiro que os levaram a desistência do curso. Já em (6) $50 \%$ estão matriculados em outros cursos, enquanto 17\% optaram por cursar Engenharia Química em uma outra IES e $83 \%$ dos desistentes em (7) não avaliam a possibilidade de retornar ao curso na UFMT. Já os itens (8-9) retratam sobre as questões socioeconômicas, na qual $83 \%$ não possuía atividade remunerada antes do ingresso e não tiveram dificuldade financeira durante a estádia na cidade, não sendo este o fator que os levaram a desistência do curso. 
Figura 5 - Análise do vínculo institucional: desistentes.
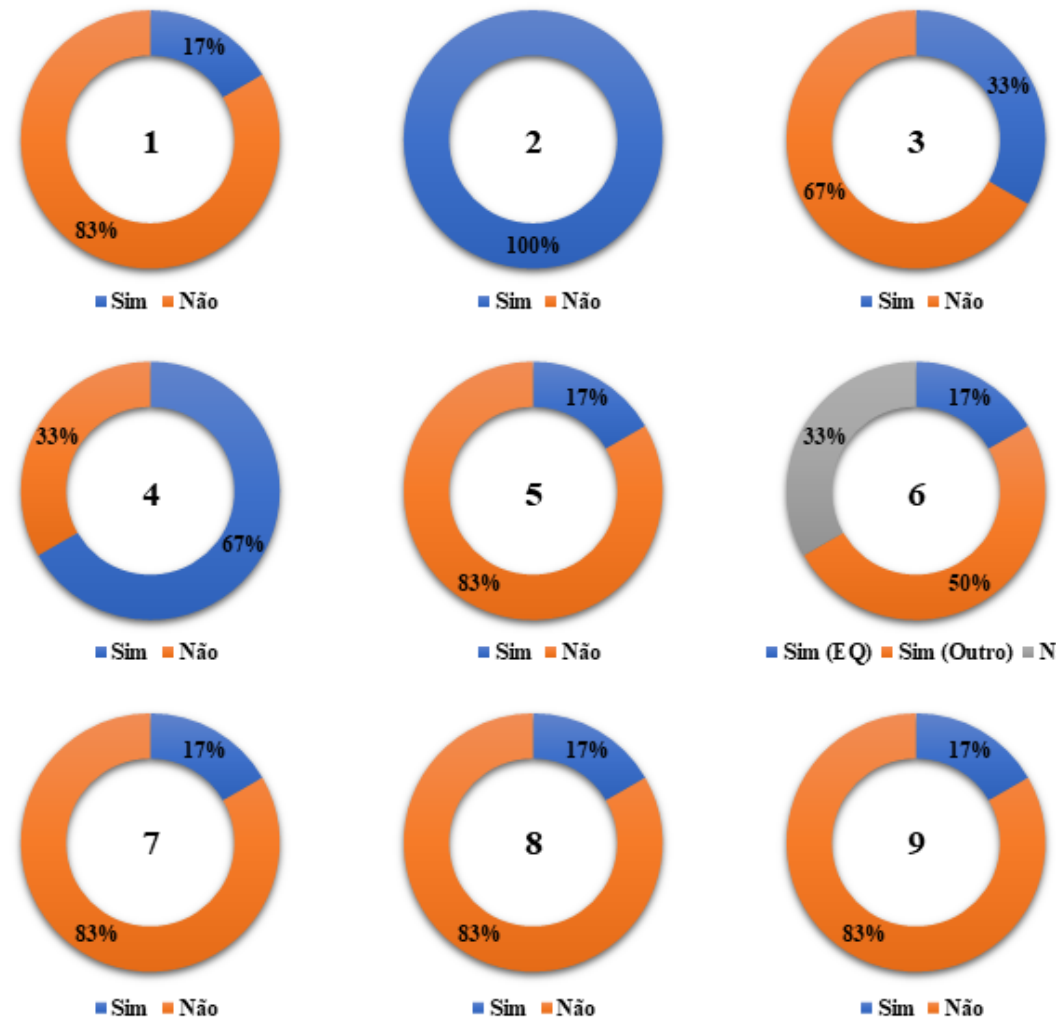

u Sim $=$ Não

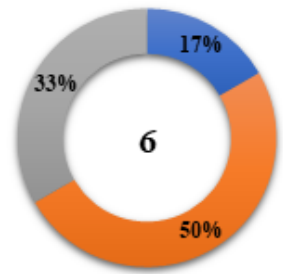

5

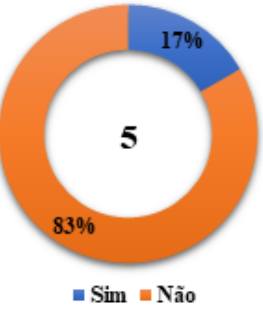

" $\operatorname{Sim}(E Q)=\operatorname{Sim}($ Outro $)=$ Não
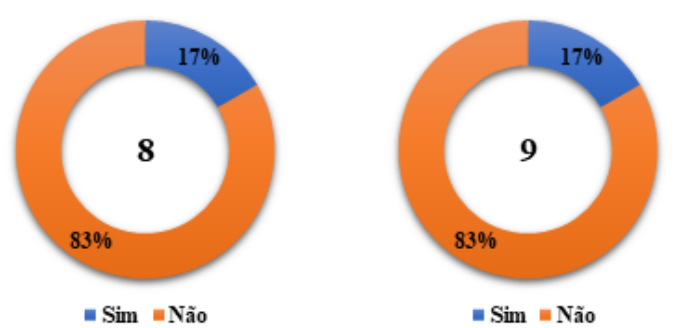

Fonte: Os autores (2021).

Posteriormente, foi realizada uma análise da autoavaliação referente aos aspectos de ensino, organização administrativa e instalações físicas do curso com todos os entrevistados. Na Figura 6, as questões foram divididas em 13 itens, com distintas abordagens. Os itens (1-2) estavam relacionados ao tópico de resolução de exercícios em sala de aula e a disponibilidade de listas, na qual 37\% consideraram mediana a forma como isso ocorre. Em (3) $26,9 \%$ consideram mediana o tempo de duração de prova, em (4) $37,3 \%$ consideram muito forte o grau de dificuldade nas provas e no item (5) avaliaram em $25,4 \%$ entre muito fraco e mediana a correção das atividades. Já em (6) 40,3\% consideram mediano a forma a adequação do conteúdo das referências bibliográficas às disciplinas e em (7) $41,8 \%$ estão satisfeitos com a pontualidade dos professores. Os itens (8-9-10) relacionam-se quanto à didática dos docentes, cerca de $32,8 \%$ em (8) consideram mediana o domínio dos professores com o conteúdo, em (9-10) $28,4 \%$ considera forte a acessibilidade e esclarecimento de dúvidas dentro ou fora da sala de aula. O último critério foi relacionado a autoavaliação a si mesmo dos discentes nos itens (11-12-13) em questões como acompanhamento na sala de aula (11) em que 44,8\% estão satisfeitos e $40,3 \%$ também estão satisfeitos com o desempenho na resolução de exercícios (12), e 37,3\% consideram mediano o tempo de estudos nas disciplinas (13). 
Figura 6 - Aspecto 1: ensino.

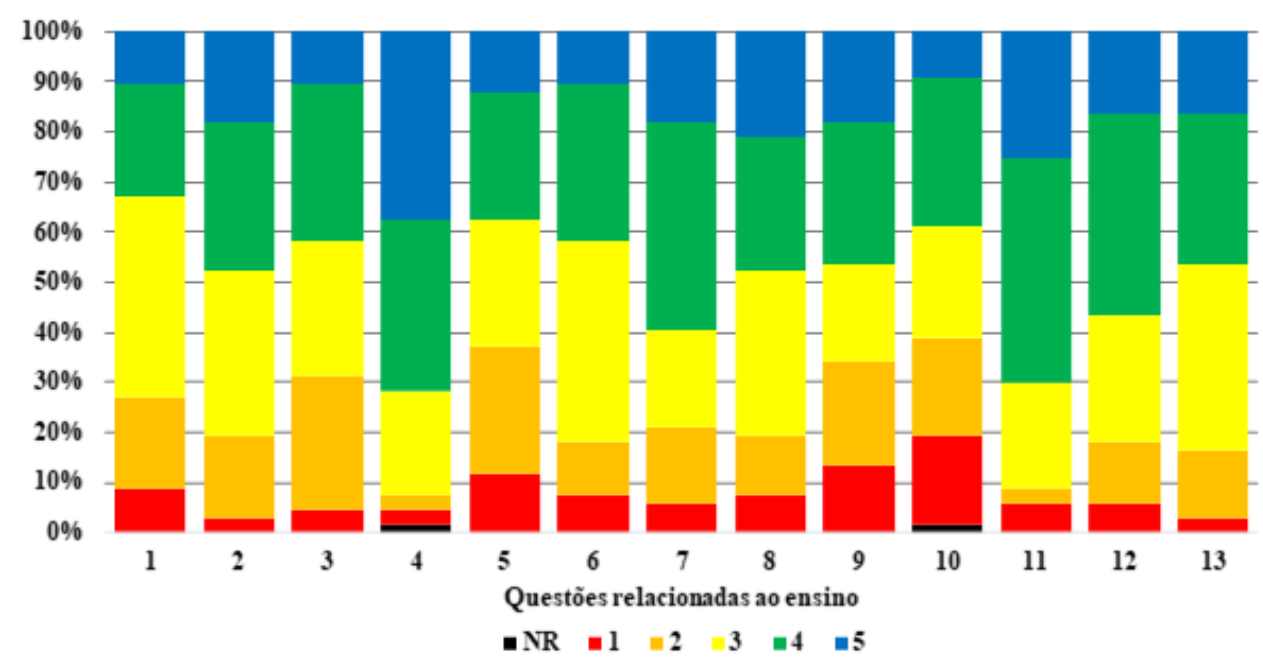

Fonte: Os autores (2021).

O próximo eixo trata sobre as questões relacionadas à organização administrativa do curso, conforme a Figura 7 . Foi feita a análise nos itens iniciais sobre a secretária acadêmica, a qual em (1-4) cerca de $48 \%$ dos entrevistados responderam como forte a relação do cumprimento, divulgação, presteza e pontualidade dos funcionários com as atividades com o curso. Em (5-8), a maioria dos discentes respondeu como muito forte os critérios relacionados ao empenho, comprometimento, desempenho e presteza do coordenador em atendê-los.

Figura 7 - Aspecto 2: organização administrativa.

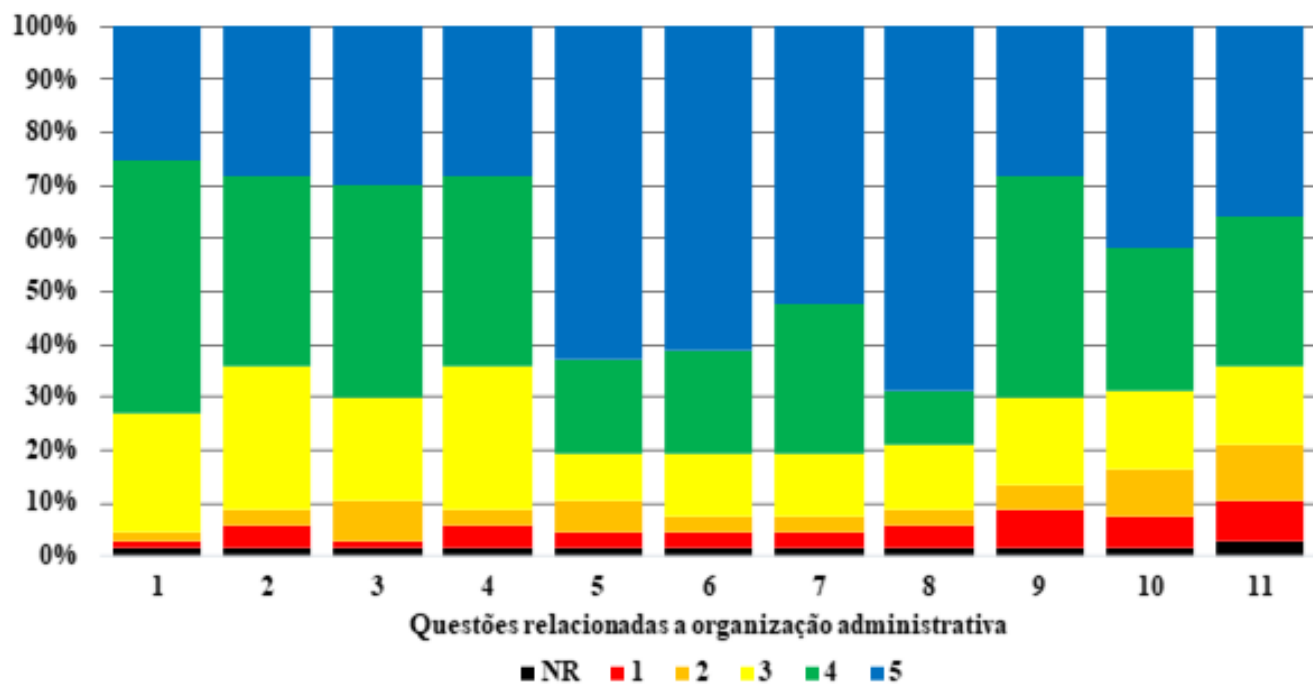

Fonte: Os autores (2021).

O último eixo analisado foi em relação às instalações físicas do campus, de acordo com a Figura 8. Os itens (1-3) tratam sobre as dimensões de espaço nas salas de aula, disponibilidade de auditórios e acesso a equipamentos de informática, na qual a maioria dos discentes responderam como mediana e forte essas relações. Em (4-6) está 
relacionado ao espaço destinado à biblioteca e seu funcionamento, a maioria dos entrevistados responderam como mediana as relações sobre horário de funcionamento, qualidade no serviço de consulta de empréstimos de livros e a quantidade de funcionários para atendimento. Já em (7) 32,8\% consideram mediana os laboratórios e instalações destinada ao curso, porém no item (8) $47,8 \%$ responderam como muito fraco equipamentos e mobílias. Por fim, os itens (9-10) discorrem sobre o funcionamento dos laboratórios e a utilização de normas e segurança, na qual os discentes responderam como mediana a sua satisfação.

Figura 8 - Aspecto 3: instalações físicas.

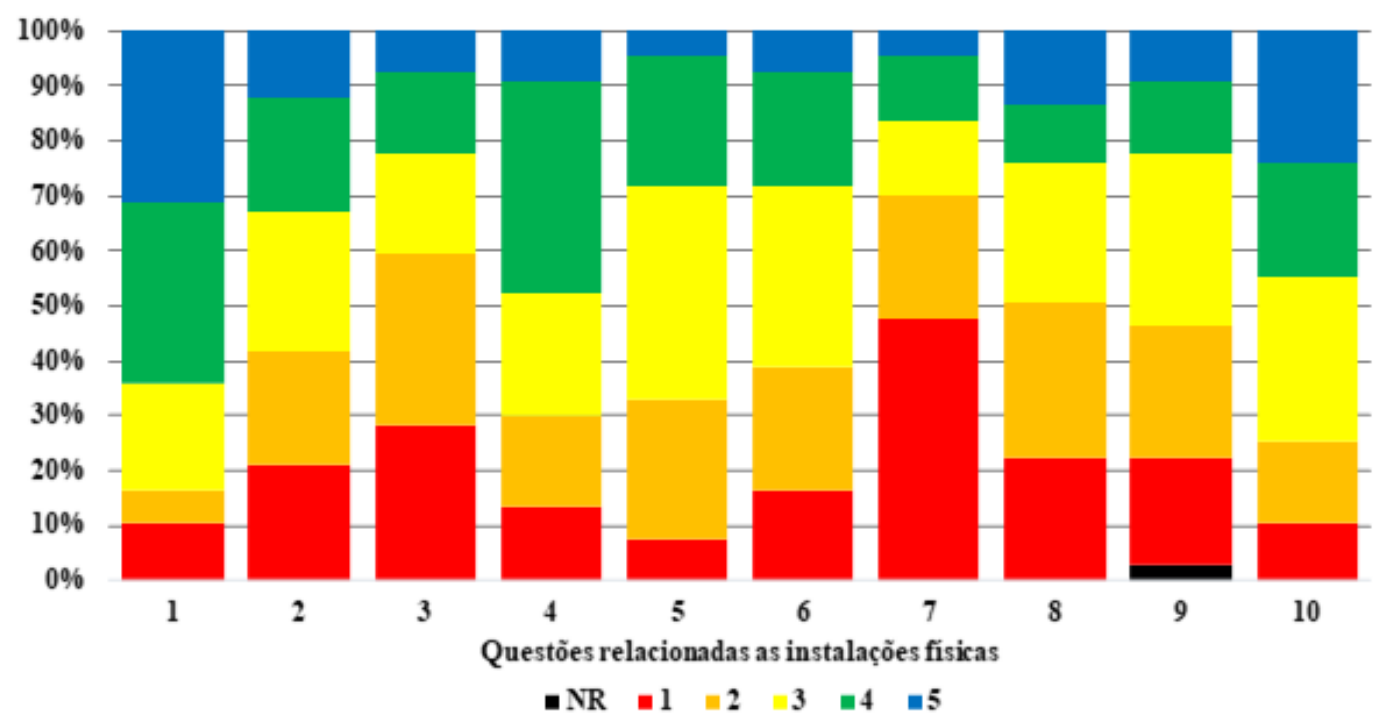

Fonte: Os autores (2021).

O aspecto 3 foi o que apresentou maior descontentamento dos alunos no curso. Esse descontentamento se deu devido ao curso de Engenharia Química estar no campus provisório.

\section{CONSIDERAÇÕES FINAIS}

Diante do que foi abordado e dos objetivos propostos pela pesquisa, conclui-se que a autoavaliação institucional é uma ferramenta necessária nas IES e que através da mesma pode-se constatar resultados diversos acerca dos assuntos abordados. Nesse sentido, constatou-se que a perspectiva dos vínculos institucionais - matriculados, desistentes e em trancamento trouxeram distintas análises sobre a autoavaliação acerca do curso de forma geral, visto que no universo da pesquisa a maioria dos entrevistados não apresentaram satisfação com o curso ou não atende/atendeu suas expectativas em questões relacionadas a matriz curricular, por exemplo. Nas abordagens relacionadas aos aspectos de ensino, por sua vez, teve respostas variando entre mediana e/ou fraco com destaque ao grau de dificuldade das provas e o domínio de conteúdo dos docentes. Dessa forma, é de suma importância a implantação do instrumento de avaliação e da necessidade de estimulá-lo, reformulá-lo e torná-lo contínuo. 


\section{Agradecimentos}

Gostaríamos de agradecer ao comitê de ética da Universidade Federal de Mato Grosso por ter apoiado nossa pesquisa, bem como os discentes do curso de Engenharia Química que responderam o formulário e fizeram esta pesquisa acontecer.

\section{REFERÊNCIAS}

AGAPITO, A.P. Ensino superior no Brasil: expansão e mercantilização na contemporaneidade. Temporalis, n.32. Brasília, 2016. Disponível em: <http://periodicos.ufes.br/temporalis/article/view/14064> Acesso em: 19 abr. 2020

ALVES, M. F. S.; MANTOVANI, K. L. Identificação do perfil dos acadêmicos de engenharia como uma medida de combate à evasão. Revista de Ensino de Engenharia, v. 35, n. 2, 2017.

CONFEDERAÇÃO NACIONAL DA INDÚSTRIA. Mais da metade dos estudantes abandona cursos de engenharia. 2013. Disponível em: $<$ https://noticias.portaldaindustria.com.br/noticias/educacao/mais-da-metade-dosestudantes-abandona-cursos-de-engenharia/> Acesso em: 25 abr. 2021

CORDASSO, J.A. et al. Fatores determinantes na evasão de acadêmicos no ensino superior: estudo em um município do norte mato-grossense. XVI Colóquio Internacional de Gestão Universitária - CIGU. Perú, 2016.

DEPRESBITERIS, L. A autoavaliação das instituições de ensino superior. Estudos em Avaliação Educacional, v.16, n.32, 2005.

FILHO, R.L. et al. A evasão no ensino superior brasileiro. Cadernos de Pesquisa, v. 37, n. 132, p. 641-659, set./dez. 2007.

GOMES, V. et al. O ensino superior no Brasil: um breve histórico e caracterização. Ciência \& Tópico, v. 42, n. 1, p. 106-129. Recife, 2018.

HUMEREZ, D.C; JANKEVICIUS, J.V. Evolução histórica no ensino superior no Brasil. 2015. Disponível em: <http://www.cofen.gov.br/enfermagem-e-formacao-artigoscientificos_31492.html> Acesso em: 19 abr. 2021

INSTITUTO NACIONAL DE ESTUDOS E PESQUISAS EDUCACIONAIS ANÍSIO TEIXEIRA. Censo da educação superior 2018. Disponível em:

$<$ http://download.inep.gov.br/educacao_superior/censo_superior/documentos/2019/censo da_educacao_superior_2018-notas_estatisticas.pdf> Acesso em: 19 abr. 2021

JUNIOR, N.M. et al. A evasão aparente entre engenharias sob a ótica da análise de redes sociais. XVII Colóquio Internacional de Gestão Universitária. Argentina, 2017.

LOPES, I.N. A prática da autoavaliação no ensino superior. Revista Multidisciplinar e da Psicologia, v.12, n.38. 2018.

MACEDO, G.M; SAPUNARU, R.A. Uma breve história da engenharia e seu ensino no brasil e no mundo: foco Minas Gerais. REUCP, v. 10, n.1. Petrópolis, 2016. 
MAPA DO ENSINO SUPERIOR. Mapa do ensino superior 2018: panorama completo da educação superior brasileira detalhado por mesorregião. Disponível em: <https://planetay.com.br/mapa-do-ensino-superior-no-brasil/> Acesso em: 25 abr.

2021

MARTINS, T.et al. Avaliação das condicionantes de retenção dos alunos de engenharia da UTFPR: bases para propostas interventivas. Congresso CLABES. 2016. Disponível em: <https://revistas.utp.ac.pa/index.php/clabes/article/view/1057> Acesso em: 25 abr. 2021

MATTA, C. M. B.; LEBRÃO, S. M. G.; HELENO, M. G. V. Adaptação, rendimento, evasão e vivências acadêmicas no ensino superior: revisão da literatura. Psicologia Escolar e Educacional, v. 21, n. 3, p. 583-591, 2017.

MINISTÉRIO DA EDUCAÇÃO. Censo 2018. Disponível em:

<http://download.inep.gov.br/educacao_superior/censo_superior/documentos/2019/apresentacao_censo_superior2018.pdf > Acesso em: 19 abr. 2021

OLIVEIRA, R. E. C.; MORAIS, A. Vivências acadêmicas e adaptação de estudantes de uma universidade pública federal do Estado do Paraná. Revista de Educação Pública, v. 24 , n. 57, p. 547-568, 2015.

PAREDES, A. S; DURHAM, E. R. Evasão do terceiro grau em Curitiba. Universidade de São Paulo, São Paulo, 1994.

RODRIGUEZ, A. Fatores de permanência e evasão de estudantes do ensino superior privado brasileiro - Um estudo de caso. Revista PUC- SP, v.5, n.1, 2011.

SILVA, K.A. et al. Autoavaliação: uma alternativa contemporânea do processo avaliativo. Revista Brasileira de Linguística Aplicada, v.7, n,1. 2007.

SISTEMA NACIONAL DA EDUCAÇÃO SUPERIOR. Roteiro de autoavaliação institucional

$2004 . \quad$ Brasília, $2004 . \quad$ Disponível em:

<http://portal.inep.gov.br/documents/186968/484109/Roteiro+de+autoavalia\%C3\%A7\%C3\%A3o+institucional+orienta\%C3\%A7\%C3\%B5es+gerais+2004/5 5b435d4-c994-4af8-b73d-11acd4bd4bd0?version=1.2> Acesso em: 29 abr. 2021.

\section{EVENT OF DISCENTS IN THE CHEMICAL ENGINEERING COURSE AT THE FEDERAL UNIVERSITY OF MATO GROSSO - UFMT: FROM THE PERSPECTIVE OF INSTITUTIONAL SELF-ASSESSMENT}

Abstract: This article deals with the result obtained through research on student dropout in the Chemical Engineering course - UFMT from the perspective of institutional and academic self-assessment. It was carried out with the purpose of verifying the reasons that lead to withdrawal from the course, related to institutional aspects of teaching, administrative organization of the course and academic bond - dropouts, locked up and 
enrolled. In order to carry out this research, a questionnaire was elaborated via "Google Form", submitted to the UFMT Ethics Committee with approval for the research and data stratification. The form was applied to students and alumni of the course (entering between the years 2014/2 and 2019/2), featuring quantitative and qualitative methodology with a descriptive and interpretive focus on data analysis. The data showed relevant results about the research, since the most critical points from the perspective of the students in relation to institutional links refer to criteria regarding the satisfaction of the course and the curriculum matrix that do not meet their expectations. The criteria related to teaching refer to the adaptability of students to the course, having rated the satisfaction with these aspects as medium or weak. Thus, the study points out that self-assessment is relevant to understand the students' point of view regarding their satisfaction with the course and should be reformulated to continually adapt to the measure of offering the possibility of creating institutional policies as a solution. avoidance of the course.

Keywords: Evasion. Self-evaluation. Institutional aspects. 